Solar quiet variation of the horizontal and vertical components of geomagnetic field using wavelet analysis.

\begin{tabular}{|r|l|}
\hline Journal: & Canadian Journal of Physics \\
\hline Manuscript ID & cjp-2018-0034.R3 \\
\hline Manuscript Type: & Article \\
\hline Author: Submitted by the & 30 -Jun-2018 \\
\hline $\begin{aligned} \text { Complete List of Authors: } \\
\text { Keyword: }\end{aligned}$ & $\begin{array}{l}\text { Falayi, E.O.; Tai Solarin University of Education, Department of } \\
\text { Ogysics } \\
\text { Ogundile, Olayinka; Tai Solarin University of Education, } \\
\text { Department of Physics } \\
\text { Adepitan, J.O.; Tai Solarin University of Education, Department } \\
\text { of Physics and Telecommunication; Tai Solarin University of } \\
\text { Education, Department of Physics and Telecommunication } \\
\text { Okusanya, Abayomi; Tai Solarin University of Education, } \\
\text { Department of Physics }\end{array}$ \\
\hline $\begin{array}{r}\text { Is the invited manuscript } \\
\text { for consideration in a } \\
\text { Special Issue? : }\end{array}$ & $\begin{array}{l}\text { Not applicable (regular submission) } \\
\text { latitudes, low latitudes }\end{array}$ \\
\hline
\end{tabular}




\title{
Solar quiet variation of the horizontal and vertical components of geomagnetic field using wavelet analysis.
}

\author{
Falayi, E.O., Ogundile, O.O., Adepitan, J.O and Okusanya, A.A \\ Department of Physics, Tai Solarin University of Education, Ijagun, P.M.B. 2118, Ijebu \\ Ode, Ogun State, Nigeria.
}

\begin{abstract}
The solar quiet variations of horizontal and vertical ( $\mathrm{SqH}$ and $\mathrm{SqZ})$ components of the geomagnetic field obtained from both the Northern Hemisphere and Southern Hemisphere of the International Real-Time Magnetic Observatory Network (INTERMAGNET) during solar maximum years of 2001 were investigated. The results show enlargement of SqH component of the geomagnetic field during the daytime, attributed to equatorial electrojet current closer to the geomagnetic equator at the electrojet stations (BNG and $\mathrm{MBO}$ ) which are produced from large eastward flow of the current. It was observed that the SqZ is positive at the southward and negative at the northward hemispheres. The SqZ is amplified at HER and HBK around the daytime. Wavelet power spectrum (WPS) based approach was employed to analyse the SqH, $\mathrm{SqZ}$, and rate of induction $(\mathrm{SqZ} / \mathrm{SqH})$ time series in a sequence of time scaling from January to December. The higher energy of $\mathrm{SqH}$ and $\mathrm{SqZ}$ of the wavelet coefficients is noticeable at a high frequency. The monthly variation rate of induction $(\mathrm{SqZ} / \mathrm{SqH})$ analyses during the solar quiet (Sq) variations are associated to the influence of equatorwards penetration of electric fields from the field-aligned current, Earth conductiviy, effect of the ocean and ionospheric conductivity.
\end{abstract}

Keywords: Solar quiet, wavelet power spectrum, geomagnetic field, high latitudes and low latitudes

\section{PACS No.: 94.05.S-.}

\section{Introduction}

The electric currents driven along the E-layer of the ionosphere generates the solar quiet (Sq) day-to-day variation. The Sq daily variation is produced mainly from solar ultraviolet heating radiation and atmospheric solar tides, which have an influence on the neutral and ionized particle 
between the height $70 \mathrm{~km}$ and $120 \mathrm{~km}$ [1-6]. The tidal winds and conductivities in the dynamo zone are considered to be the major components influencing the pattern and strength of the Sq current system. In [7] the longitudes, seasons, years and solar cycle have influence on pattern and structure of the Sq variation. The significance of tidal winds for the production of the Sq current has been investigated using different numerical modeling [8]. Several literature have analysed the Sq variation with Earth's magnetic field, equatorial electrojet, solar long-term variations and solar activity [9-15]. In [16] it is established that it is compulsory to comprehend Sq behaviour and investigate the cause of day to day variation. The daily amplitude of the Sq variation is determined by the ionospheric conductivities, the dynamo electric field, the solar diurnal tide, and the E-region electron concentration. The currents flowing in the ionosphere also induced counterpart currents in the Earth's conducting interior and in the oceans, roughly showing the electric current flow in the ionosphere [17].

Wavelet spectrum analyses are strong technique used by different applied field. It enables the breakdown of data, functions into different time-frequency. Wavelet spectrum analyses are covariant under translation and dilatation. The wavelet-based techniques developed set of very powerful spectral analysis tools that used to examine the periodic features in non-stationary signals and examine their temporal evolution on the time-frequency difference [18-22]. In [23] wavelet transformation is used to estimate solar cycles from sunspot numbers. The same tools were used to determine the solar activity using sunspot number, geomagnetically induced current (GIC) and horizontal geoelectric field [24-27].

In the present work, we used geomagnetic field data to analyse the hourly variation of solar quiet variation $\mathrm{SqH}$ and $\mathrm{SqZ}$ at six geomagnetic observatories during geomagnetic maximum in the year 2001. We use the wavelet spectrum to investigate mean monthly variations of $\mathrm{SqH}$ and $\mathrm{SqZ}$ and monthly mean variation of induction $(\mathrm{SqH} / \mathrm{SqZ})$.

\section{Data and method of analysis}


We examine the geomagnetic field data recorded at six stations covering both the Northern Hemisphere and Southern Hemisphere collected from International Real-Time Magnetic Observatory Network (INTERMAGNET) [28] during the geomagnetic maximum years of 2001. Table 1 illustrates the geographic and geomagnetic locations of the stations. The days when the high value of the planetary geomagnetic disturbance index $\mathrm{Kp}$ is less than or equal to 2 is referred to as geomagnetically quiet days [29]. Five geomagnetically quiet days from ten internationally quiet days (IQDs) in each month for the year 2001 were selected. The internationally quiet days (IQDs) were collected from Geoscience Australia website (http://www.ga.gov.au/oracle/ geomag/iqd form.jsp) [30]. We employed the same method used by [31-32] which considered the variation in $H(\Delta H)$ and $Z(\Delta Z)$ which is computed by correcting the hourly departure and the midnight baseline values for non-cyclic variation to obtain $\mathrm{SqH}$ and $\mathrm{SqZ}$ respectively. The $\mathrm{SqH}$ and $\mathrm{SqZ}$ diurnal variations for the five quietest days over a month are used to investigate mean monthly values of $\mathrm{SqH}$ and $\mathrm{SqZ}$ for six magnetic observatories in 2001 .

\section{Table 1. Geographic and geomagnetic coordinates of geomagnetic observatory.}

\subsection{Hourly Mean Variation of $\mathrm{SqH}$ and $\mathrm{SqZ}$}

The hourly mean values of $\mathrm{SqH}$ and $\mathrm{SqZ}$ from the six geomagnetic observatories were analysed as well as the time gradient, as shown in Figure 1 (a and b). The daily variation of $\mathrm{SqH}$ at BAN and $\mathrm{MBO}$ shows a maximum variation around noon time. The maximum $\mathrm{SqH}$ is noticed within the electrojet region due to equatorial electrojet EEJ phenomena. It was established in [33], that when the $\mathrm{SqH}$ is at 12:00 hr, it implies that the sun is vertically overhead and solar activity is at peak on any day and at any station, as displayed in Figure 1 ( $a$ and b). The effective conductivity of the EEJ is the cowling conductivity that flows along the eastward direction at and in the vicinity of the dip equator [34-35]. It was also noted that ESK NUR, HER and HBK showed reversal of equatorial electrojet current (EEJ) during geomagnetically quiet periods in the afternoon section, with the presence of counter electrojet (CEJ) as described in [32] (see Figure 
1a). When the Sq and EEJ are moving opposite to each other and a westward EEJ current exceeds the eastward Sq current counter electrojet is produced.

Figure 1(a-b): Hourly variation of $\mathrm{SqH}$ and $\mathrm{SqZ}$ respectively at $\mathrm{BNG}, \mathrm{MBO}, \mathrm{HBK}$, HER, NUR and ESK.

The HBK and HER located at southern hemisphere of the magnetic equator, shows that SqZ display the effect of the EEJ with peak values during the midday hours and 14:00 hr while the SqZ displays negative in the afternoon hours at MBO, ESK and NUR (see Figure 1b). The observation confirms the suggestion of [36] that SqZ at HER and HBK might be influenced by the induced currents due to the eastward and westward ionospheric currents. The maximum values of $\mathrm{SqH}$ and $\mathrm{SqZ}$ are greater during the daytime than the nighttime due to solar activity in consistency with atmospheric dynamo theory [37].

\subsection{Wavelet spectrum analyses of $\mathrm{SqH}$ and $\mathrm{SqZ}$}

We use wavelet analysis to determine the technique of variation and to break-down time series into time-frequency space. The wavelet analysis function produces low duration, high frequency, high duration and low frequency. The functions can be used to represent low bursts of long frequency or long duration slowly varying signals. Both the exponential and Gaussian function are referred to as Morlet wavelet given in equation (1)

$$
\psi_{0}(\eta)=\pi^{\frac{1}{4}} \exp \left(i w_{o} \eta\right) \exp \left(-\eta^{2} / 2\right)
$$

where $\psi_{0}$ represents wavelet value of non-dimensional for time $\eta$, while $w_{0}$ denotes nondimensional for frequency. For a wavelet to be admissible, the function must be zero mean and constrained in time and frequency space. The equation (2) is called scaled wavelet 


$$
\psi\left[\frac{\left(n^{l}-n\right) d t}{s}\right]=\left(\frac{d t}{s}\right)^{\frac{1}{2}} \psi_{0}\left[\frac{\left(n^{l}-n\right) d t}{s}\right],
$$

where s denotes dilation variables applied to vary the scale and $\mathrm{n}$ denotes the translation variable employed to slide in time. The $s^{-1 / 2}$ denotes a normalization function used to retain the energy of the scaled wavelet constant. The time series values is denoted as $X_{n}$ and $n$ is the time index. Each of the values are separated by constant time interval dt. The convolution of the wavelet component with the original time series is called wavelet transforms $\mathrm{W}_{\mathrm{n}}(\mathrm{s})$. The symbol (*) represents the complex conjugate in equation 3.

$$
W_{n}(s)=\sum_{n^{l}=0}^{N-1} X_{n^{l}} \psi *\left[\frac{\left(n^{l}-n\right) d t}{s}\right] .
$$

Mother wavelet can be used to break down time series into time-frequency phase space. In this section we used the wavelet spectrum to examine $\mathrm{SqH}$ and $\mathrm{SqZ}$ and $\mathrm{SqZ} / \mathrm{SqH}$.

Figure 2 (a-f) depicts the wavelet spectrum analyses of SqH of BNG, ESK, HBK, HER, MBO and NUR respectively during the maximum year of 2001. At BNG, the SqH current maximum variation on month basis was observed in January, February, May, June, September and October. At ESK, the intensity of $\mathrm{SqH}$ is amplified in the month of March. The SqH current variation is amplified in the month of April, May, September and October at HBK. March and April depict the maximum of $\mathrm{SqH}$ current at HER. The maximum $\mathrm{SqH}$ current variation was noticed in February, June and October at MBO. At NUR, low power concentration of $\mathrm{SqH}$ was observed in January, March, May and June.

\section{Figure 2 (a-f). Wavelet spectrum analyses of SqH of BNG, ESK, HBK, HER, MBO and NUR respectively during maximum year of 2001.}

The vertical component geomagnetic $(Z)$ field is very sensitive to the local inhomogenities of the Earth's internal conductivity. Figure 3 (a-f) depicts the computed wavelet power spectrum of the SqZ at BNG, ESK, HBK, HER, MBO and NUR. In this case, the time series correspond to 
the values measured during the year 2001. A well defined peak corresponding to the monthly variation during the year is depicted in Figure 3 (a-f). The shape and amplitude of these SqZ variations depend on geographic latitude of the location. The monthly variations of SqZ are generally considered regular and smooth for all the months of the year. The SqZ field variation has a main spatial dependence on latitude including level of solar activity.

Figure 3 (a-f). Wavelet spectrum analyses of SqZ of BNG, ESK, HBK, HER, MBO and NUR respectively during maximum year of 2001 .

Figure 4 (a-f) shows the spectra of the mean ratio of $\mathrm{SqZ} / \mathrm{SqH}$ at low, mid and high latitudes in the northern and southern hemispheres. The analysis of induction $(\mathrm{SqZ} / \mathrm{SqH})$ using geomagnetic time series through wavelet transform showed the dominant period. At BNG, the most prominent rate of induction $(\mathrm{SqZ} / \mathrm{SqH})$ of WPS between the month of February and April (see Figure 4a). At ESK, the dominant period SqZ/SqH was noticed between April - May, and July - August and October - November (Figure 4b). Figure 4c depicts the maximum power spectrum between the month of March and April. Another peaks was noticed between the month of August and September at HBK. At HER, January and February exhibit power spectrum of induction rate (Figure 4d). Figure 4e shows that February - March, May - June and September - October exhibit power spectrum at MBO. In Figure 4f, power spectrum concentration of SqZ/SqH was observed in May - July and October - December at NUR. The power spectrum of induction rate exhibits a notable latitudinal dependency, with enormous amplitudes at both hemispheres.

Figure 4 (a-f). Wavelet spectrum analyses of SqH/SqZ of BNG, ESK, HBK, HER, MBO and NUR respectively.

\subsection{Discussion of the results.}

Figure 1 ( $\mathrm{a}$ and b) display the observed geomagnetic field variations in the $\mathrm{SqH}$ and $\mathrm{SqZ}$. Significant trends in the daily amplitude of the SqZ variation are obtained using geomagnetic field data for MBO, BNG, HBK, HER, NUR and ESK. The enlargement of eastward E and northward $\mathrm{B}(\mathrm{ExB})$ is as a result of the increase in vertical Hall polarization field which produce 
large electrical conductivities over the magnetic equator. Figure 1a depicts large positive variations in $\mathrm{SqH}$ current and higher daily range of the horizontal geomagnetic $(\mathrm{H})$ field intensity during the daytime attributed to equatorial electrojet current closer to the geomagnetic equator at the electrojet stations (BNG and $\mathrm{MBO}$ ) which are produced from large eastward flow of the current. Also, the reduction in the SqH component of the geomagnetic field at NUR, ESK, HBK and HER is noticed, which is an indication of the westward flow of the current. This is as a result of a decrease in the eastward electrojet strength affirming a westward electrojet current flow [3840] (see Figure 1a). Figure 1b shows an opposite sign from the northern hemisphere to the southern hemisphere of the SqZ. It is positive at the southward and negative at the northward hemispheres of the SqZ. It was noted that the SqZ is amplified around the midday time, which is much stronger at the southward hemisphere (HBK and HER) than the northern hemisphere.

The wavelet analysis used in this study produces unbiased and steady estimation of the wavelet power spectrum (WPS). Also, the method identifies the time series variability. This periodicity appears as a dominant and persistent feature in the wavelet amplitude spectra. The colour bars range from blue to red which implies a low power to high power respectively. More so, the significant regions are the ones linked with red and orange, which depicts the numerical intensity of coupling between the two variables. The red colour stipulates maximum frequency contributing to the energy of signal over that interval. The component of the signal corresponding to the daily variation during the month appears in all the six stations. Figures 2 and 3 display the wavelet spectral analysis of the signal of $\mathrm{SqH}$ and $\mathrm{SqZ}$ at BNG, ESK, HBK, HER, MBO and NUR. The high energy of the wavelet coefficients is more notable at a high frequency. This might be influenced by ionospheric conductivity in high latitudes and ionospheric vortices might have influence on low latitudes due to the atmospheric heating effects. Low wavelet coefficients of induction were also observed. The seasonal shift in the mean position of the Sq current system of the ionospheric electrojet resulted to seasonal change in the $\mathrm{SqH}$ and $\mathrm{SqZ}$ variations. The consequence of seasonal variation is the electrodynamics effect on local winds, The winds are subjected to daily and seasonal variability [41]. 
Variation in the $\mathrm{Z}-\mathrm{H}$ relationship is as a result of non-uniformities in the conductivity of the upper mantle. The significant peaks in Figure 4 (a-f) show a strong modulation rate of induction $(\mathrm{SqZ} / \mathrm{SqH})$ intensity using geomagnetic time series through wavelet transform. This shows the dominant period between January and December 2001. It was observed that the fluctuations have a signature of the scaling spectral exponent computed by linear regression fitting of the scaling of the five quiets date. The rate of induction effect on the wavelet power spectrum at BNG and $\mathrm{MBO}$ at low latitudes is attributed to the equatorial electrojet by ionospheric currents flowing at the dip equator with high current intensities. The authors in [42 - 43] suggested that the rate of induction can be affected by auroral electrojet, substorms onsets, geomagnetic pulsation and sudden impulses. The amplification rate of induction might depend on temporal and spatial structure of the ionospheric currents source and distribution of the conductivity in the Earth. The rate of induction analyses during the quiet day variations are associated to the influence of equatorwards penetration of the electric fields from the field-aligned current, Earth conductivities, the effect of the ocean and ionospheric conductivities [44].

\section{Conclusion}

The study presents the variation in $\mathrm{SqH}, \mathrm{SqZ}$ and $\mathrm{SqZ} / \mathrm{SqH}$ at BNG, ESK, HBK, HER, MBO and NUR, during the solar maximum year of 2001. It was observed that the $\mathrm{SqH}$ is maximum around the daytime which is much intensified at $\mathrm{MBO}$ and $\mathrm{BNG}$. The reduction in $\mathrm{SqH}$ component of the geomagnetic field reflect the westward flow of the current, which is as a result of a decrease in the eastward equatorial electrojet intensity confirming a westward electrojet current flow at ESK, NUR, HBK and HER. The SqZ is amplified at HBK and HER around the midday time.

\section{Acknowledgements}

The authors thank INTERMAGNET for the provision of the geomagnetic field data (http://www.intermagnet.org/data). Also the staff of Australia Geosciences for the provision of internationally quiet days (IQDs) calendar (http://www.ga.gov.au/oracle/

\section{geomag/iqd form.jsp)}




\section{References}

[1] S. Chapman and J. Bartels., Geomagnetism, Vol. I, Clarendon press, Oxford 1940.

[2] P. N. Mayaud. Ann. Geophys., 21, 514-544 (1965).

[3] S. Matsushita, and H. Maeda. J. Geophys. Res., 70, 2535- 2558 (1965).

[4] R. J. Stening. An assessment of the contributions of various tidal winds to the Sq current system, Planet. Space Sci., 17, 889-908 (1969)

[5] J. D. Tarpley. Planet. Space Sci., 18, 1091-1103 (1970). doi:10.1016/0032-0633(70)90110-8.

[6] M. Takeda and H. Maeda. J. Geophys. Res., 85(A12), 6895-6899 (1980) doi:10.1029/JA085iA12p06895.

[7] S. Matsushita. Solar quiet and lunar daily variation fields, in Physics of Geomagnetic Phenomena, edited by S. Matsushita and W. H.Campbell, pp. 302-424, Academic Press, Orlando, Fla. (1967).

[8] N. M. Pedatella, J.M Forbes, J.M., and A.D Richmond . Journal of geophysical research, 116, a04317, (2011). doi:10.1029/2010ja016289.

[9] R. Sellek. Atmos. Sol. Terr. Phys., 42, 689-695 (1980).

[10] D. M. Schlapp, R. Sellek, and E. C. Butcher. Geophys. J. Int., 100, 469-475 (1990)

[11] M. J. Takeda. Geophys. Res., 107(A9), 1252 2002. doi:10.1029/2001JA009210.

[12] S. Macmillan and A. Droujinina. Earth Planets Space, 59, 391-395 (2007).

[13] J. M. Torta, L. R. Gaya-Piqu'e, J. J. Curto, and D. J. Atmos. Sol.-Terr. Phys., 71, 14971510 (2009), doi:10.1016/j.jastp.2008.06.006,

[14] A. G. Elias, M. Zossi de Artigas, and B. F. de Haro Barbas. J. Geophys. Res., 115, A08316 (2010). doi:10.1029/2009JA015136.

[15] I. Cnossen,, A. D. Richmond, and M. Wiltberger. J. Geophys. Res., 117, A05302 (2012). doi:10.1029/2012JA017555.

[16] J. M. Torta, M .J. Juan Santiago, J. Curtto, J and L. R. Gaya-Pique. Earth Planets Space, 62, 297-307, (2010).

[17] B. H. Barbas, A. G. Elias, I. Cnossen, and M. Z. Artigas. J.Geophys. Res., Space Physics, 118, 3712-3718 2013. doi:10.1002/jgra.50352, (2013).

[18] G. Strang, and T. Nguyen. Wavelets and Filter Banks. Wellesley-Cambridge Press, 490 pp 1996.

[19] E. Foufoula-Georgiou, and P. Kumar, 1994. Wavelets in Geophysics, San Diego, Academic Press.

[20] I. Daubechies. Ten Lectures on Wavelets. Society for Industrial and Applied Mathematics, Philadelphia, pp. 357-360 (1992).

[21] M. B. Ruskai, G. Beylkin, R. Coifman, I. Daubechies, S. Mallat, Y. Meyers, and L. Raphael, (eds.), 1992. Wavelets and Their Applications, Jones and Bartlett Publishers.

[22] C. K. Chui. An Introduction to Wavelets. Academic Press, 264 (1992).

[23] A. R. Ochadlick, H. N Kritikos and R. Giegengack, R. Geophys. Res. Lett., 20, 1471-1474 
(1993).

[24] D. V. Hoyt and K. Schatten. Solar Physics, 181, 491-512 (1998)

[25] P. Frick, S. Baliunas, D. Galyagin, D. Sokoloff and W. Soon. Ap. J. 483, 426-434 (1997).

[26] E.O. Falayi, O. Ogunmodimu, O.S. Bolaji, J.D. Ayanda and O.S. Ojoniyi. NRIAG Journal of Astronomy and Geophysics, 6, 131-140 (2017a)

[27] E.O. Falayi, B.O. Adebesin and O.S. Bolaji. Adv. Space Res. (2017b), https://doi.org/10.1016/j.asr.2017.11.005.

[28] INTERMAGNET. 2018. International Real-time Magnetic Observatory Network. Available from: http://www.intermagnet.org/.

[29] [30] Y. Yamazaki, K. Yumoto, M. G. Cardinal, B . J Fraser, P. Hattori, Y. Kakinami, J. Y. Liu, K. J. W. Lynn, R Marshall, D. McNamara, T. Nagatsuma, V. M Nikiforov, R. E. Otadoy, M. Ruhimat, B. M. Shevtsov, K. Shiokawa, S. Abe, T. Uozumi and A. Yoshikawa. Journal of geophysical research, 116, a10312, (2011) doi:10.1029/2011ja016487,.

[30] Geoscience Australia website (http://www.ga.gov.au/oracle/ geomag/iqd form.jsp)

[31] A. B. Rabiu, A. I Mamukuyomi and E.O Joshua. Bull. Astr. Soc. India 35, 607-618 (2017).

[32] O.S. Bolaji, J. O. Adeniyi, I. A. Adimula, S. M. Radicella, P. H. Doherty. J. Atmoph. and Sol-Terres. Phys. 98, 1-11 (2013).

[33] A.B. Rabiu, K.Yumoto, E.O. Falayi, O.R.Bello, MAGDAS/CPMN Group. Sun and Geosphere, 6(2): $63-66,2011$

[34] C. A. Onwumechili .and P.O. Ezema. J. Atmos. Terr. Phys, 39, 1079, 1977

[35] J. M. Forbes, J. Rev. Geoph. Space Phys., 19, 469, 1981.

[36] R. G. Rastogi, T. Kitamura, and K. Kitamura. Annales Geophysicae, 22, 2729-2739, 2004.

[37] A. B Rabiu, I. A. .K ., Adimula., K. Yumoto, J.O. Adeniyi, and G. Maeda, G. Earth, Moon, and Planets, 104, 173-179, 2009.

[38] S. Chapman. Geofisica Pura e Applicata 19, 151-158. 1951

[39] S. Alex, B. D Kadam, D. R. K. Rao. Journal of Atmospheric and Terrestrial Physics 60, 371-379, 1998.

[40] R. G. Rastogi. Atmospheric and Terrestrial Physics 60, 1471-1476, 1998

[41] P. Gouin and P. N. Mayaud Ann. Geophys., 23, 41-47, 1967.

[42] D.H. Boteler, R.J Pirjola, and H. Nevanlinna. Adv. Space Res. 22, 17 (1998). doi:10.1016/S0273-1177(97)01096-X.

[43] A. Viljanen, E.I. Tanskanen, and A. Pulkkinen. Ann. Geophys. 24, 725 (2006). doi:10.5194/angeo-24-725-2006

[44] E. O. Falayi, A. B. Rabiu, O. S. Bolaji, R. S. Fayose. Can. J. Phys. 93, 1156-1163 (2015). 
Figure Captions

(a)

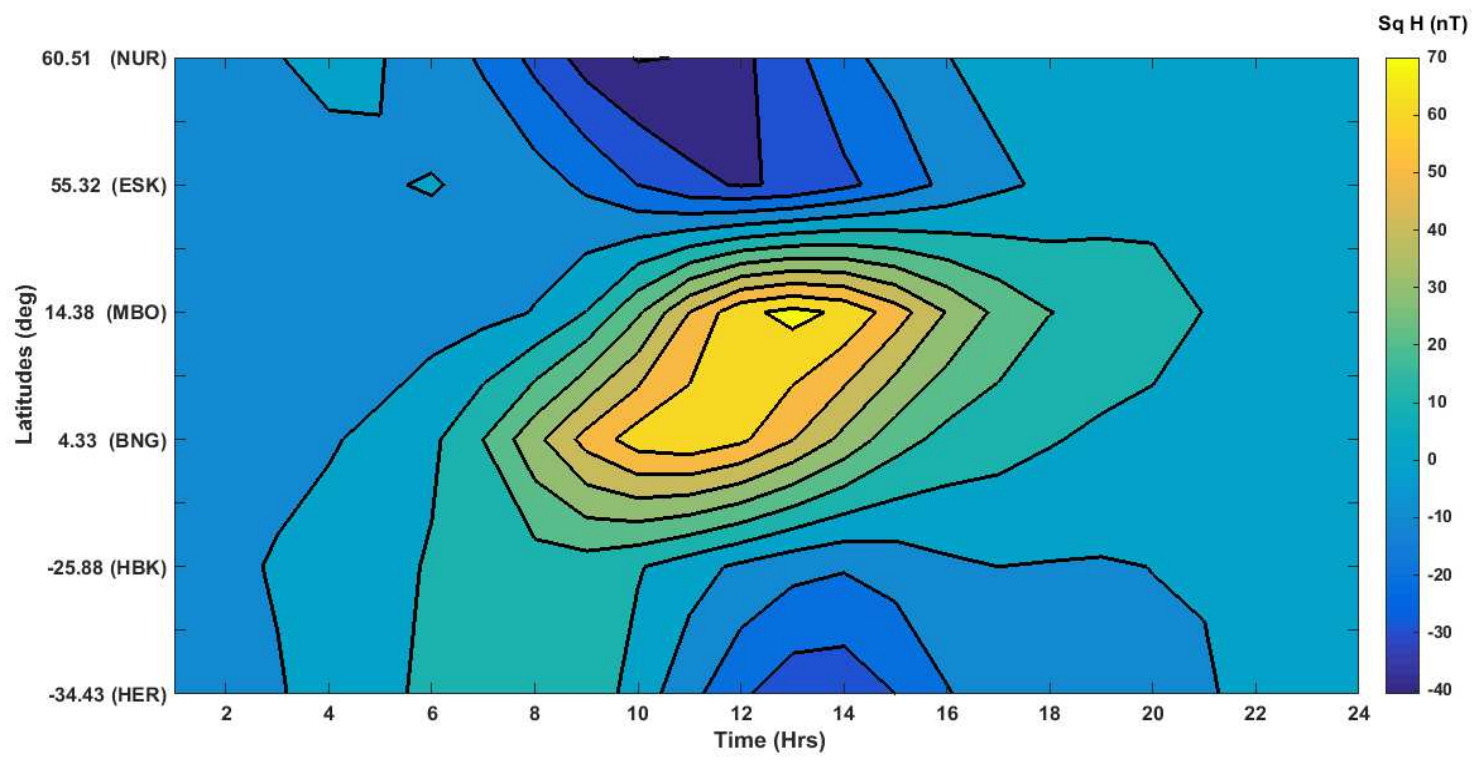

(b)

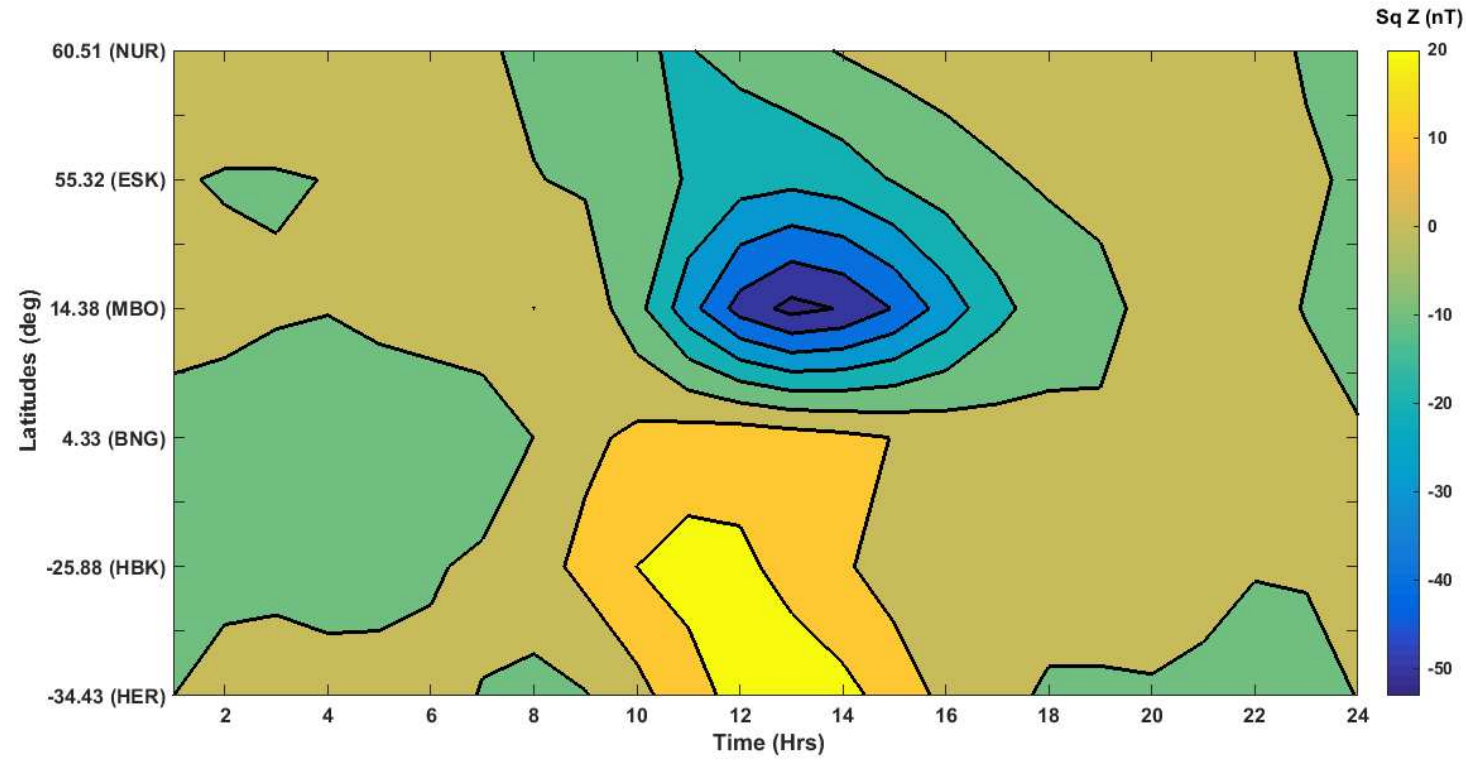

Figure 1(a-b): Hourly variation of $\mathrm{Sq} H$ and $S q \mathrm{Z}$ respectively at $\mathrm{BNG}$, MBO, HBK, HER, ESK NUR. 
(a)

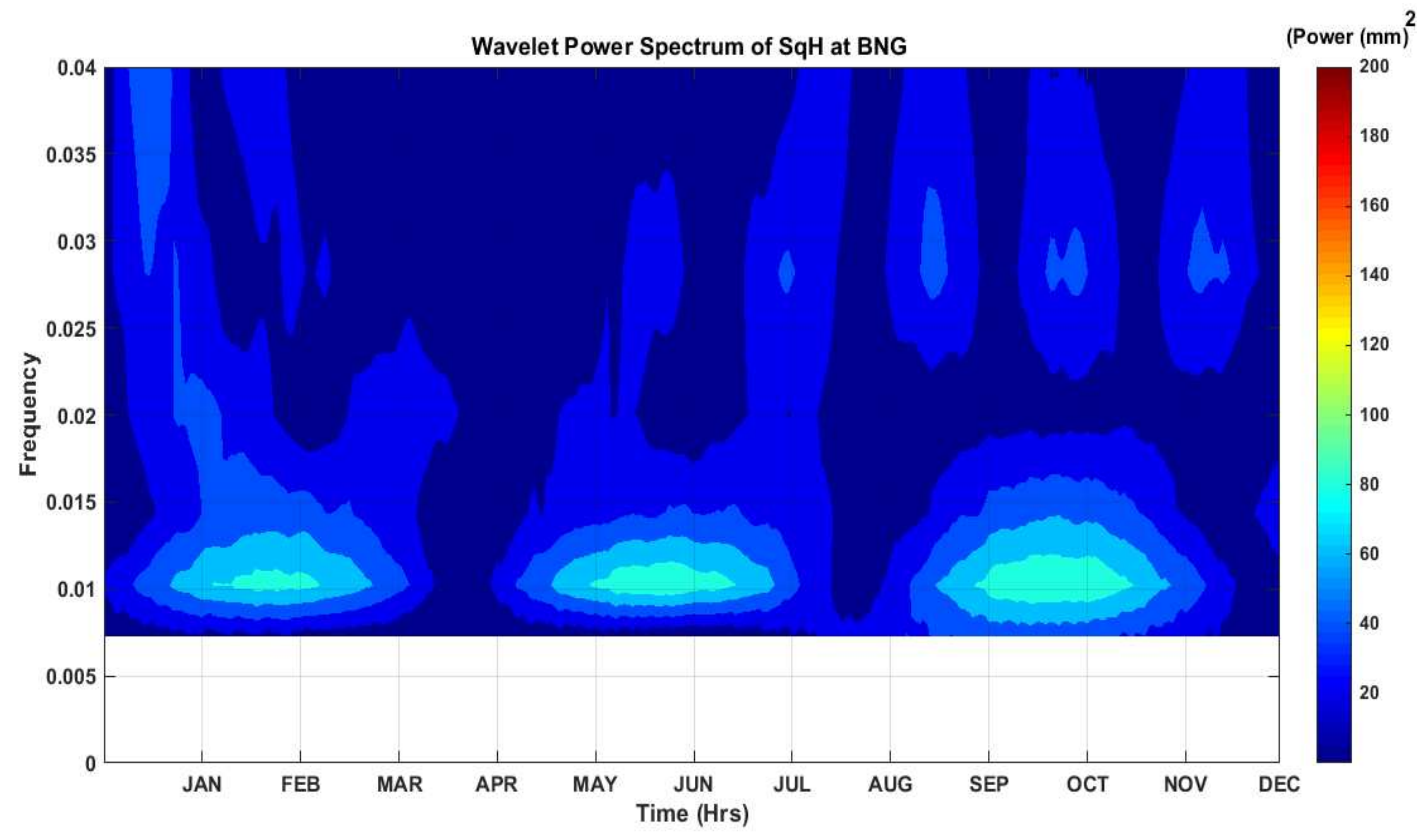

(b)

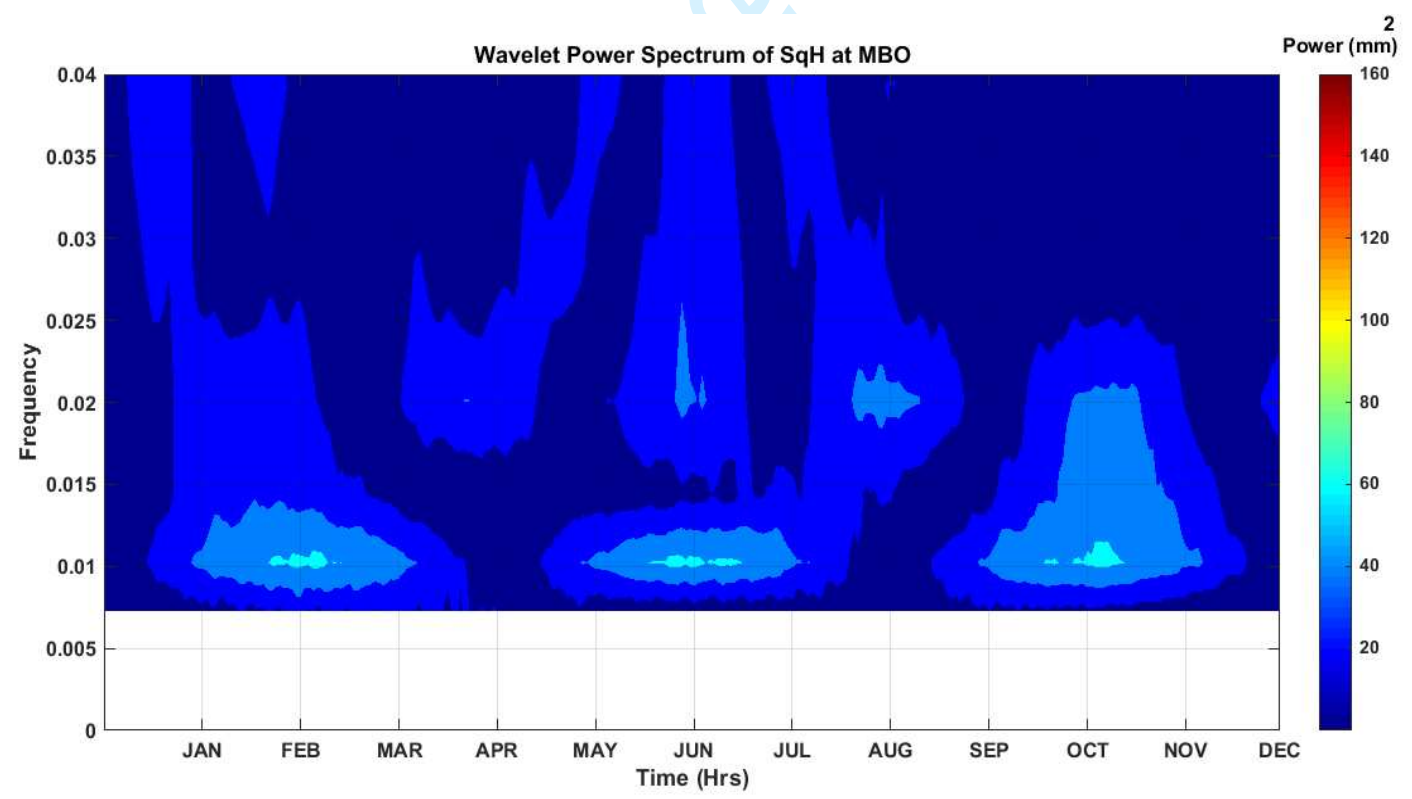


(c)

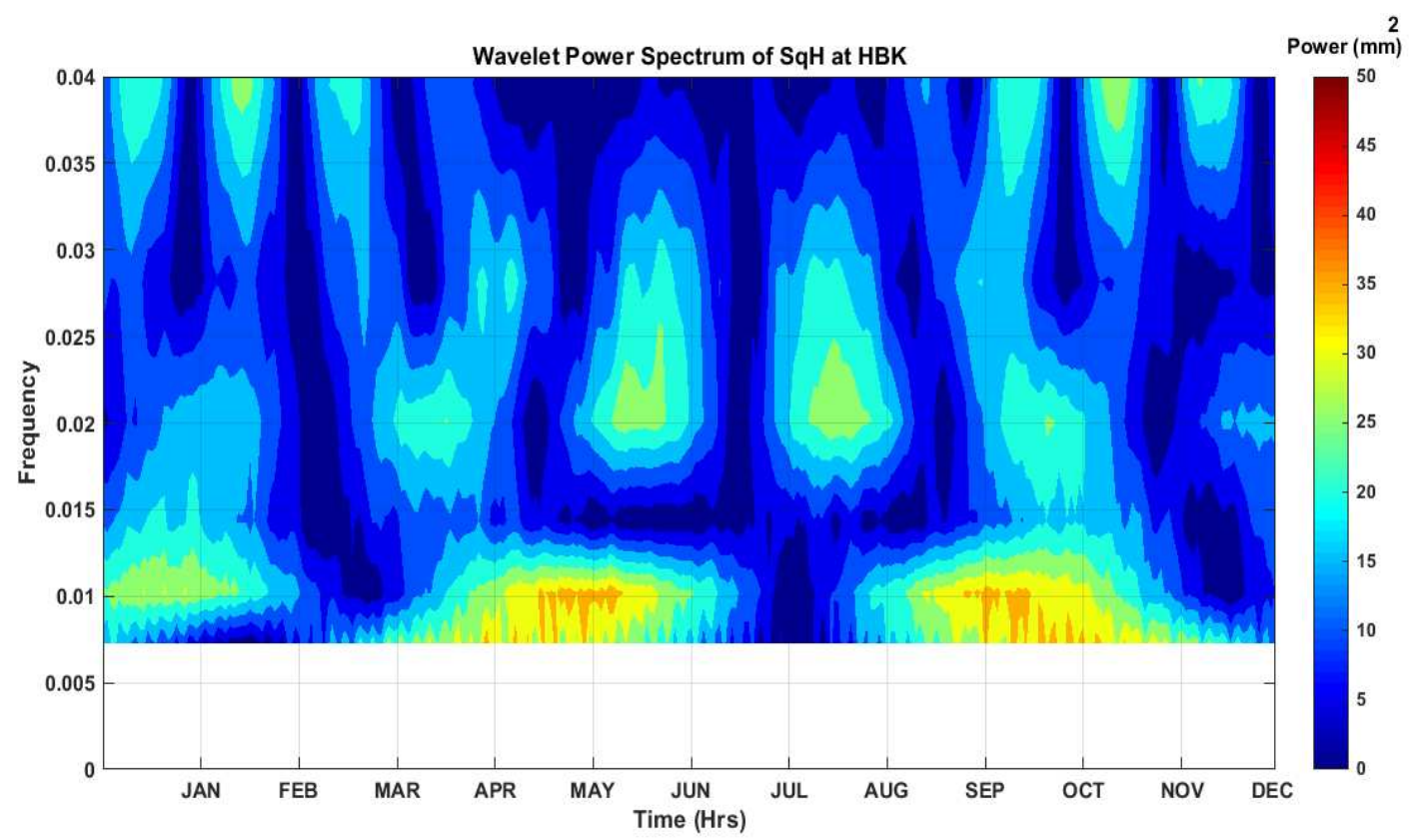

(d)

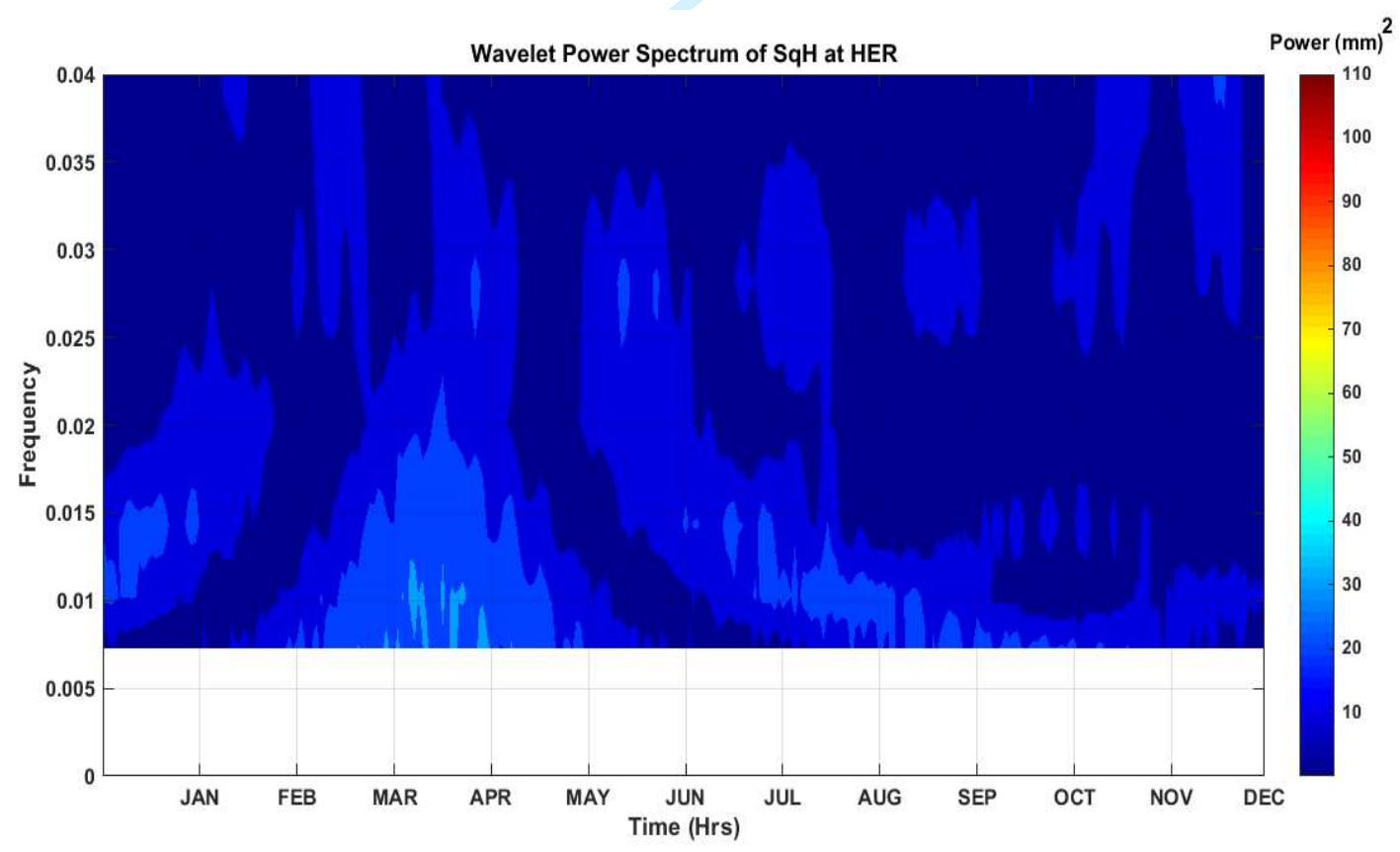


(e)

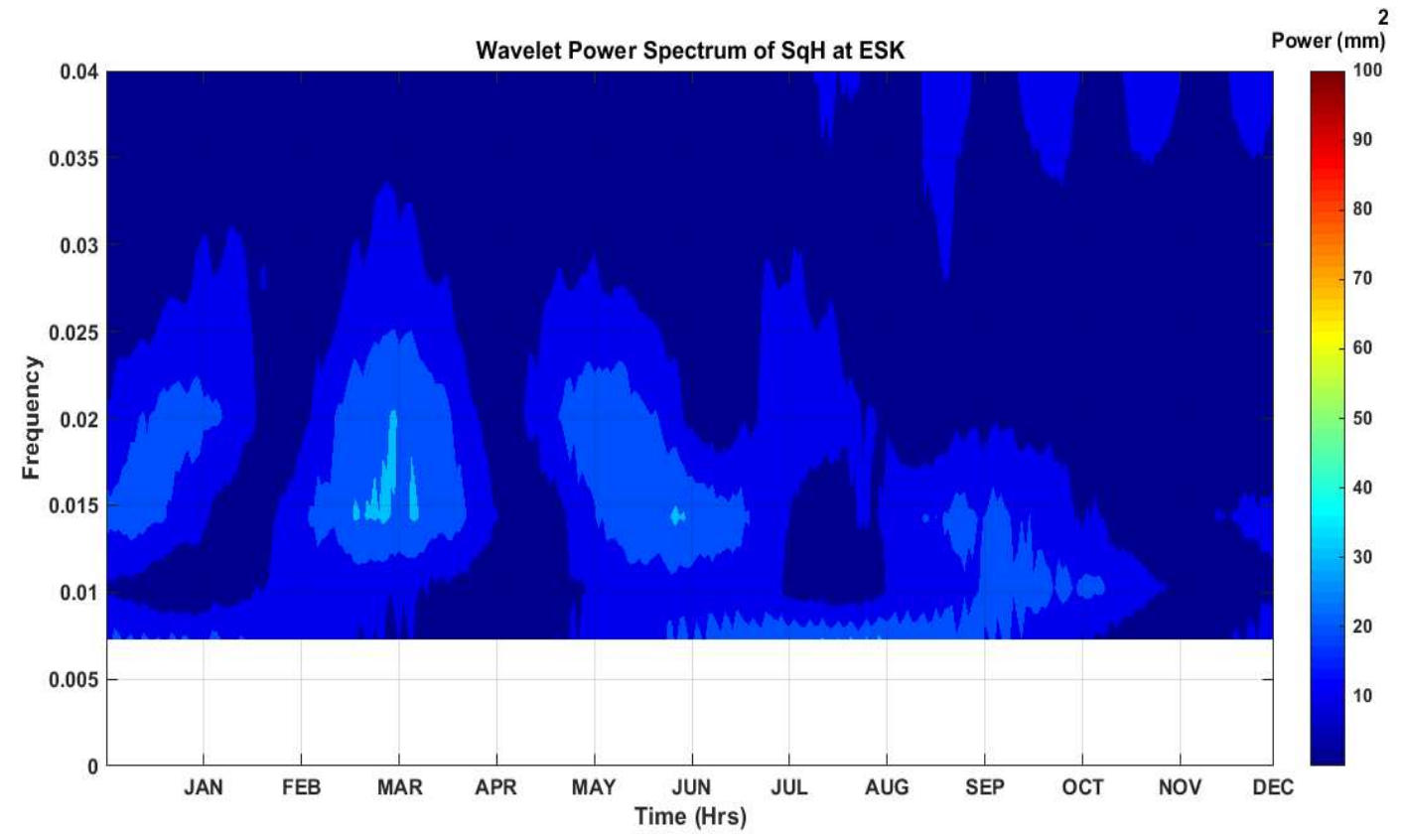

(f)

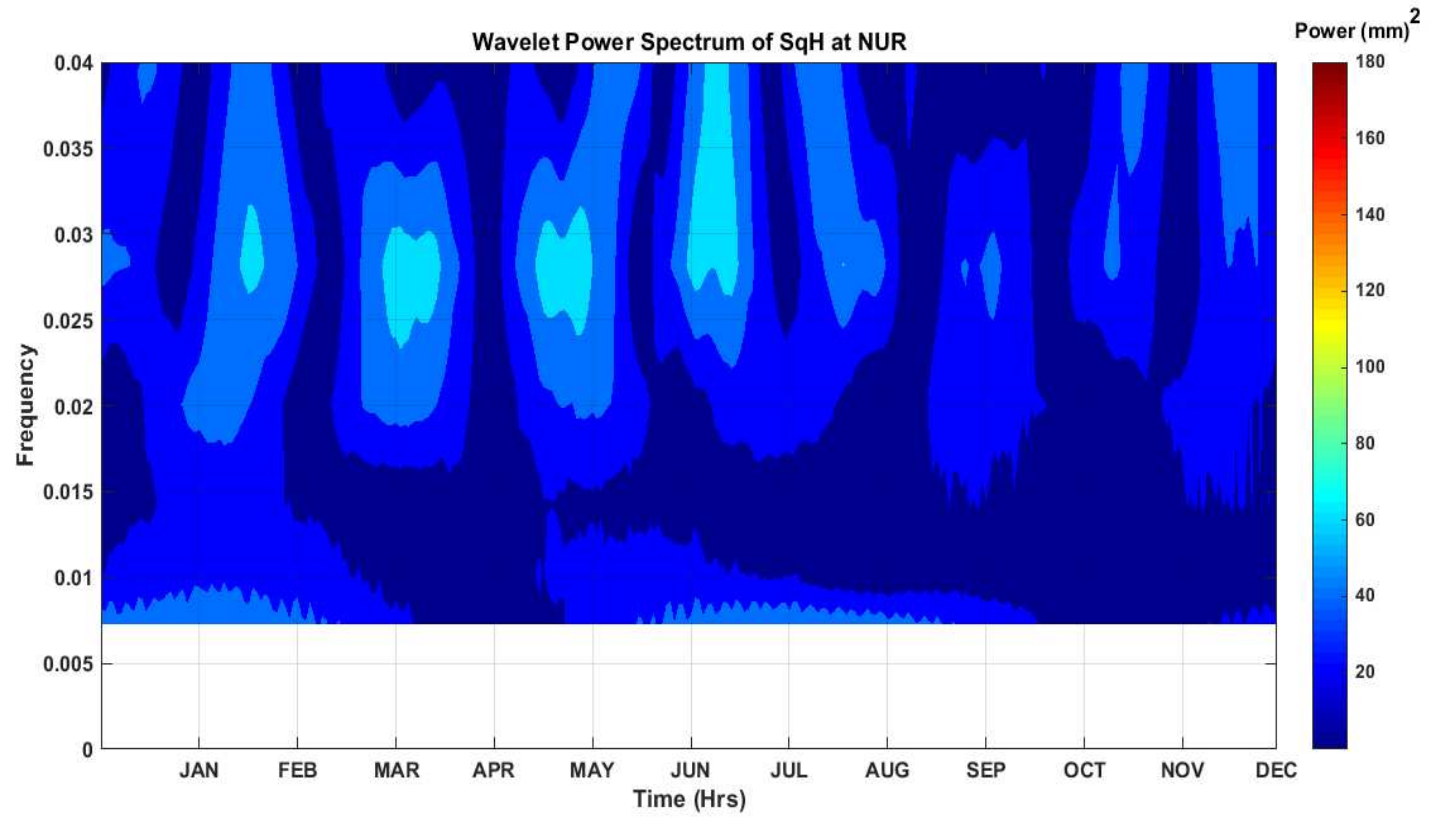

Figure 2 (a-f). Wavelet spectrum analyses of SqH at BNG, MBO, HBK, HER, ESK and NUR respectively during the solar maximum year of 2001 . 
(a)

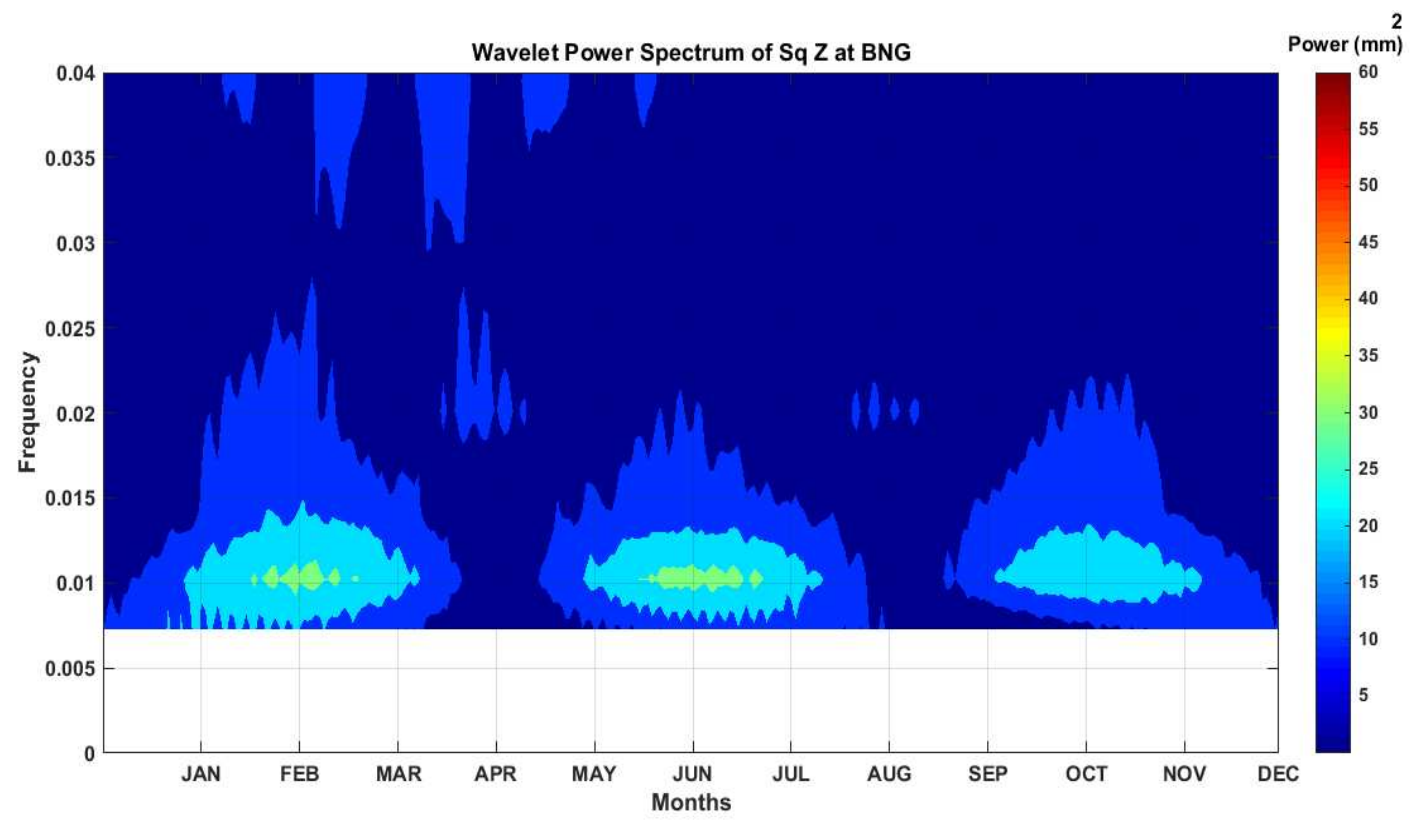

(b)

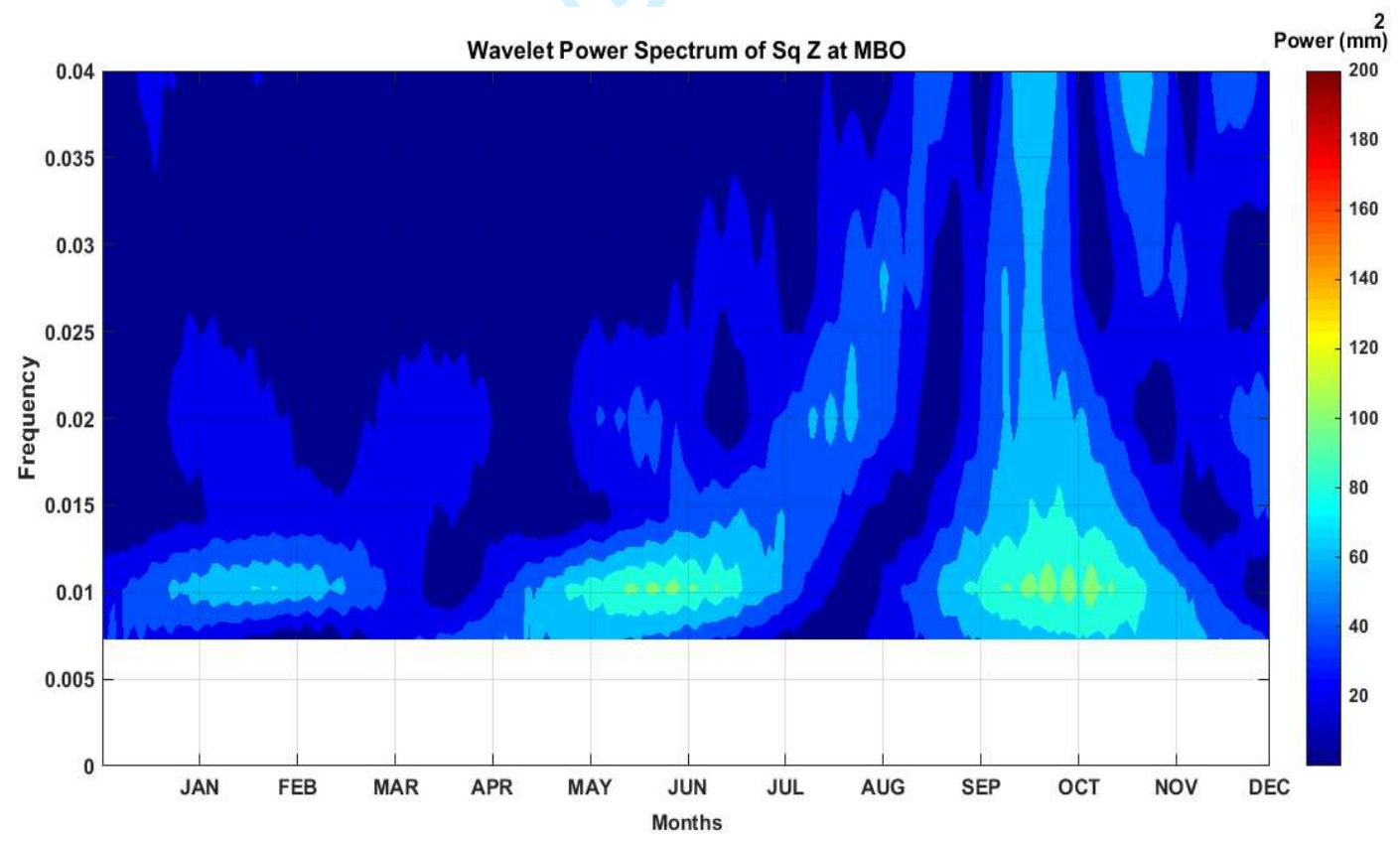


(c)

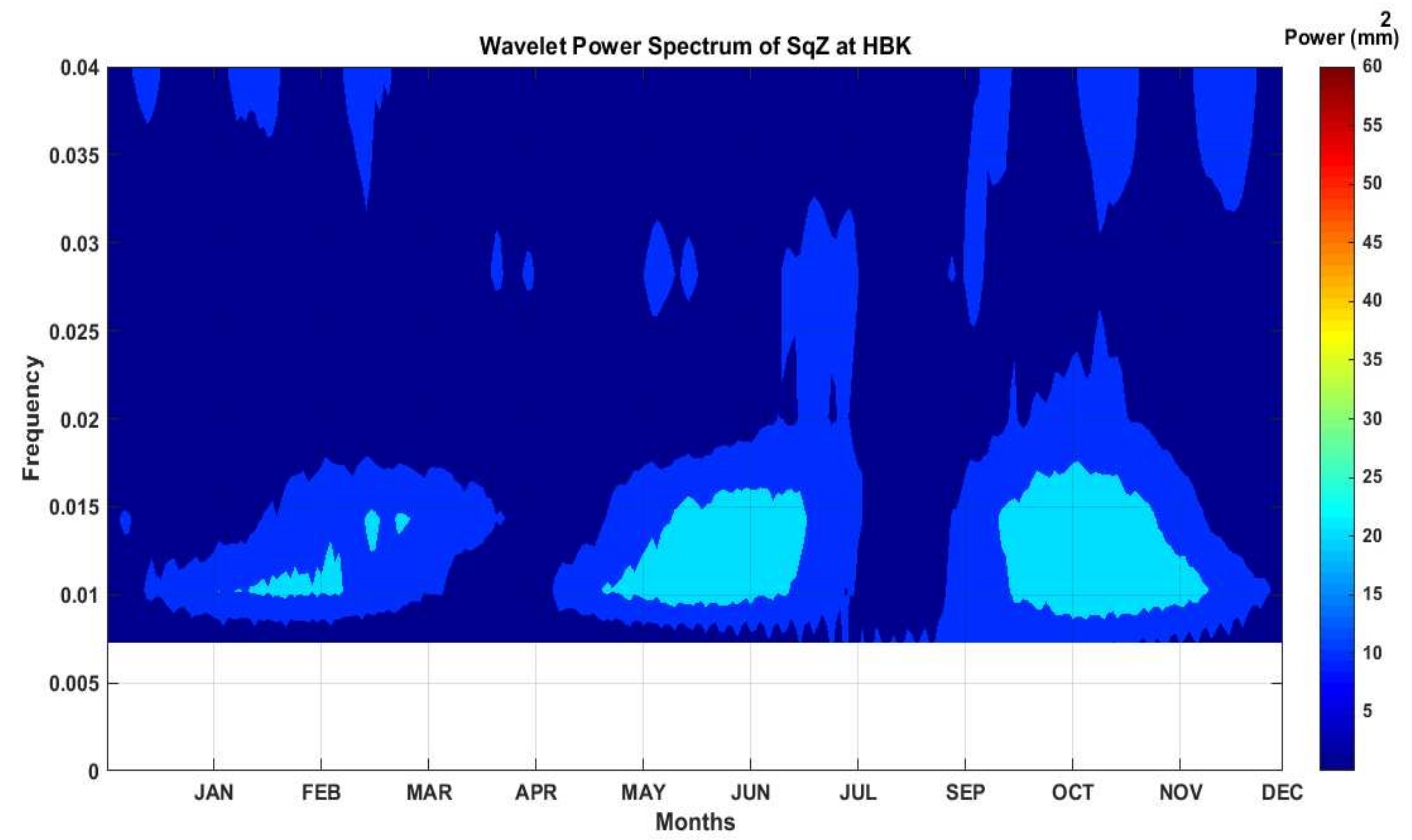

(d)

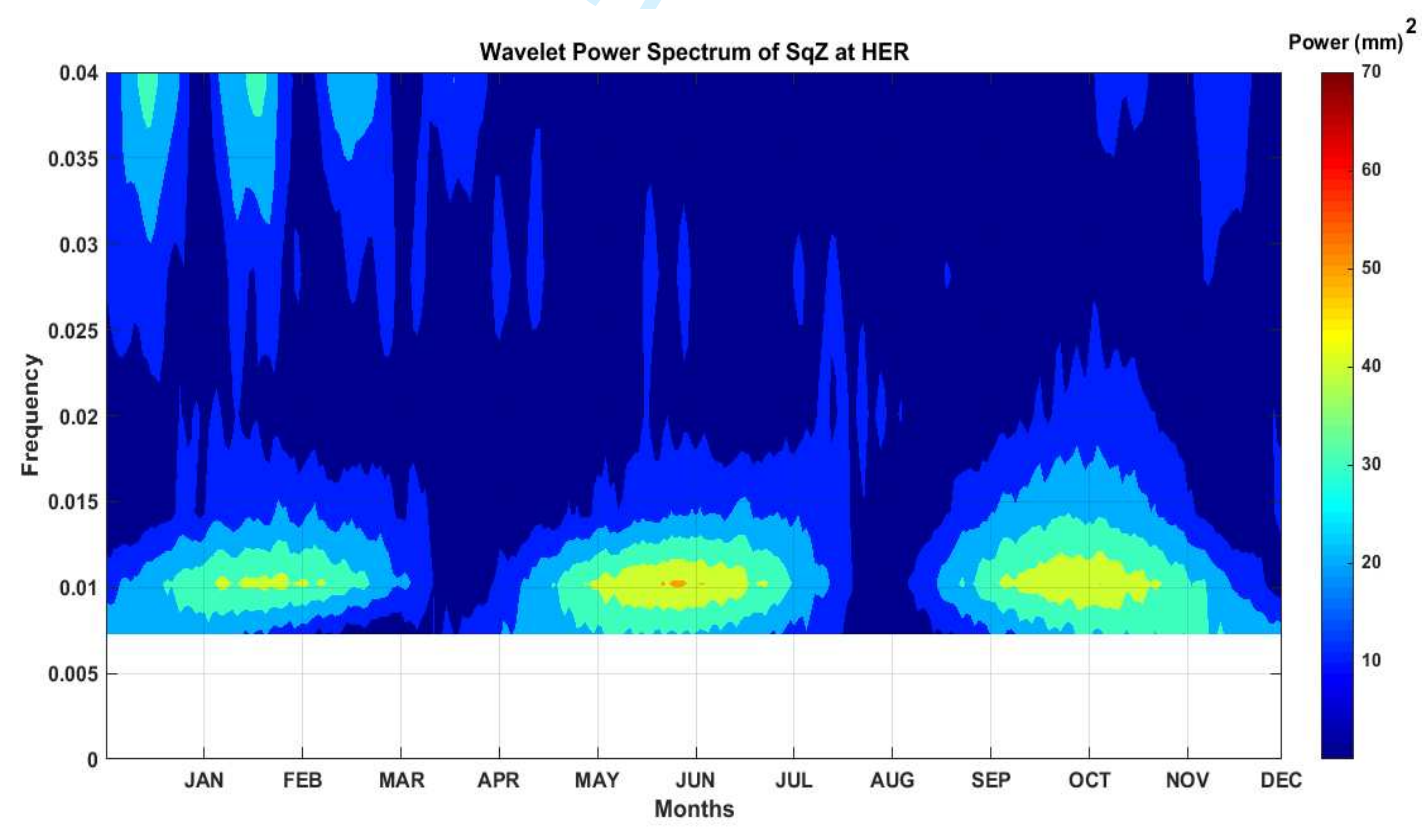


(e)

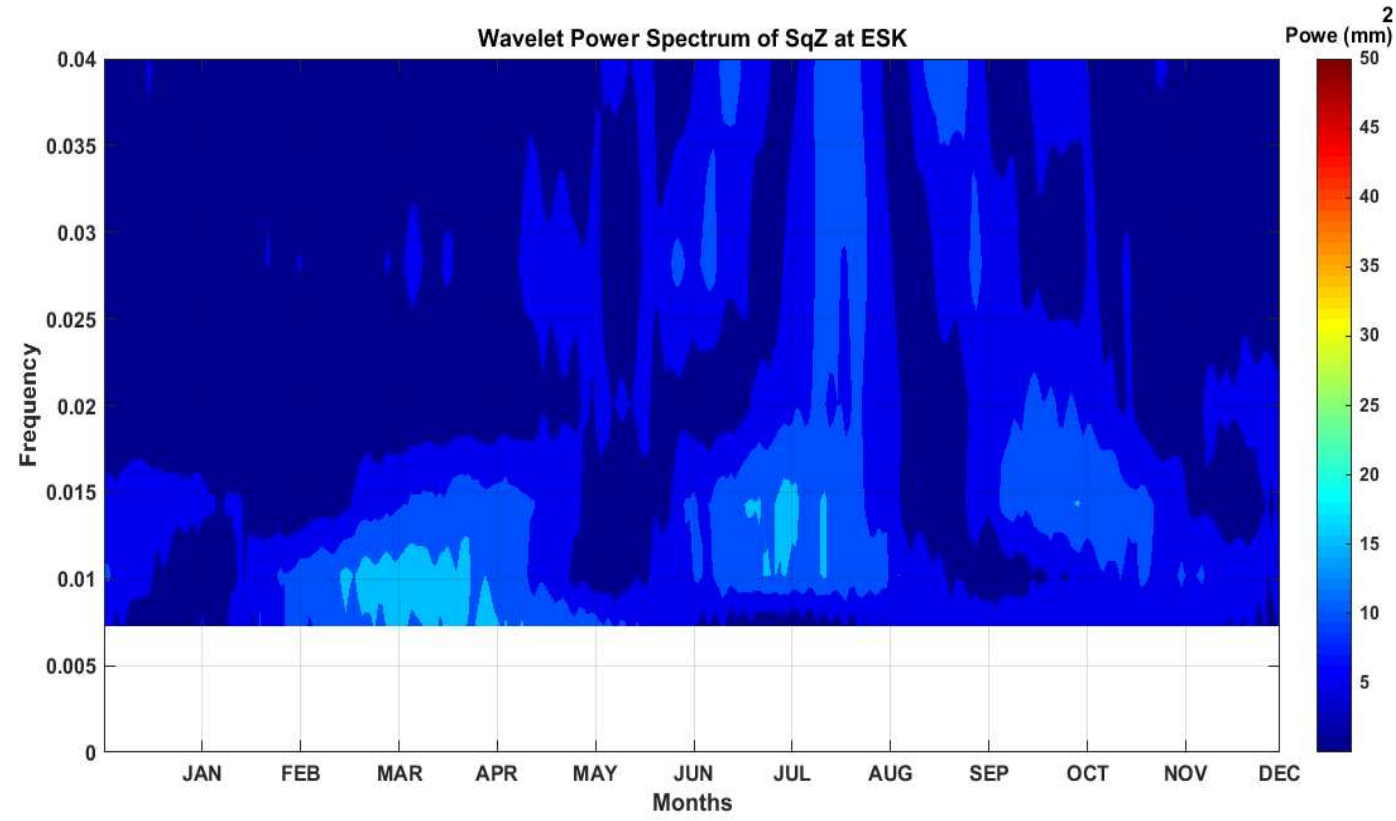

(f)

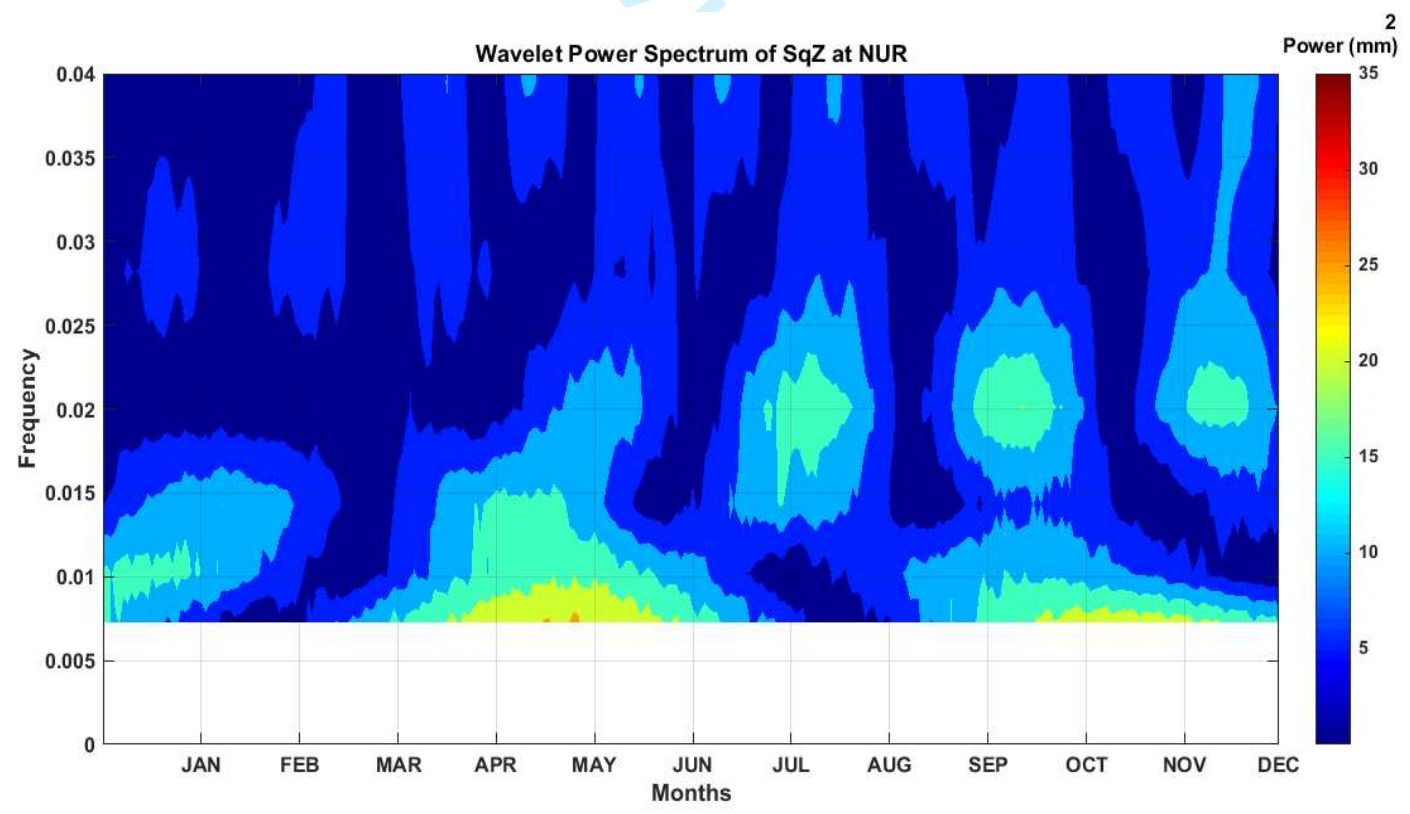

Figure 3 (a-f). Wavelet spectrum analyses of SqH at BNG, MBO, HBK, HER, ESK and NUR respectively during the solar maximum year of 2001 . 
(a)

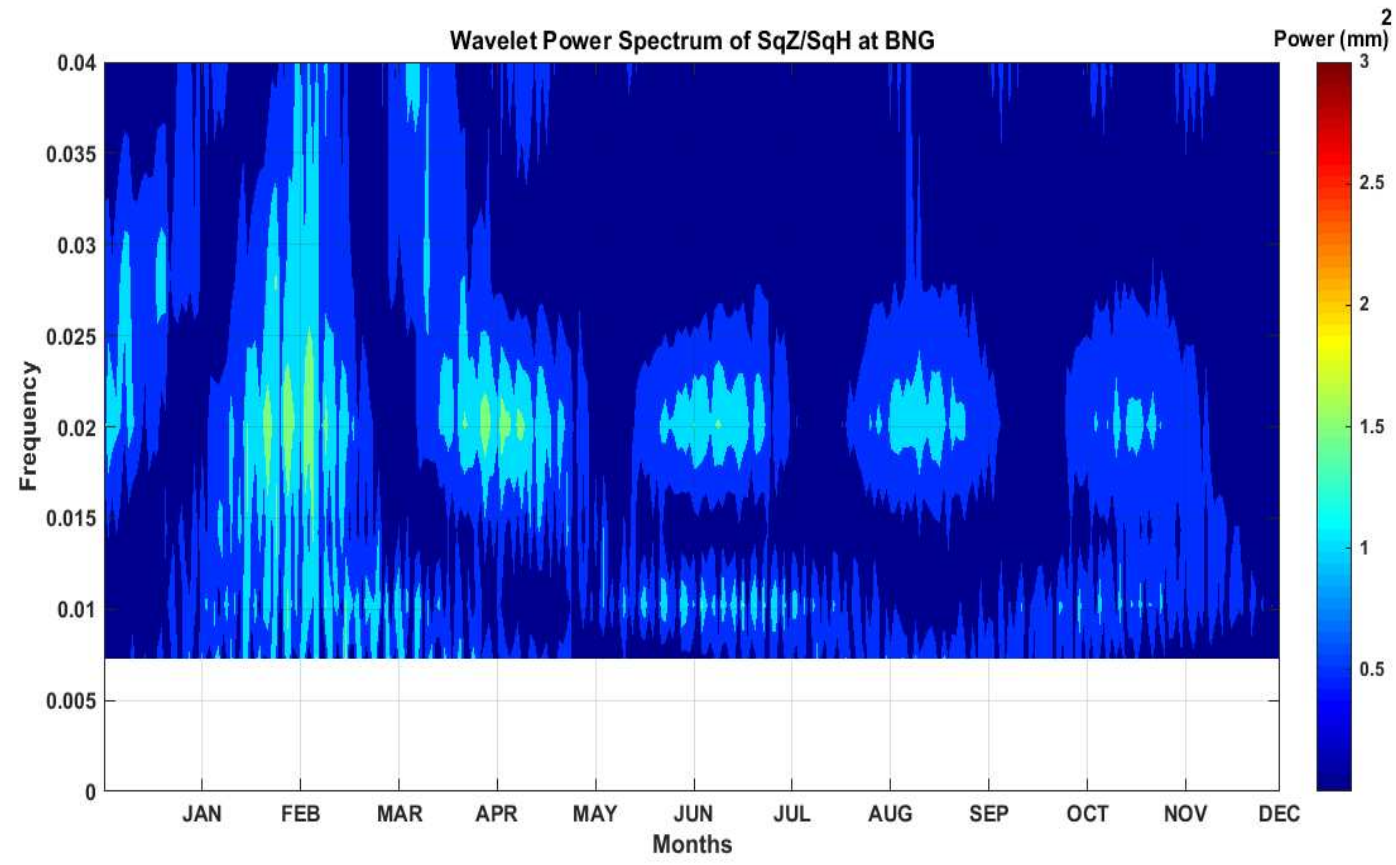

(b)

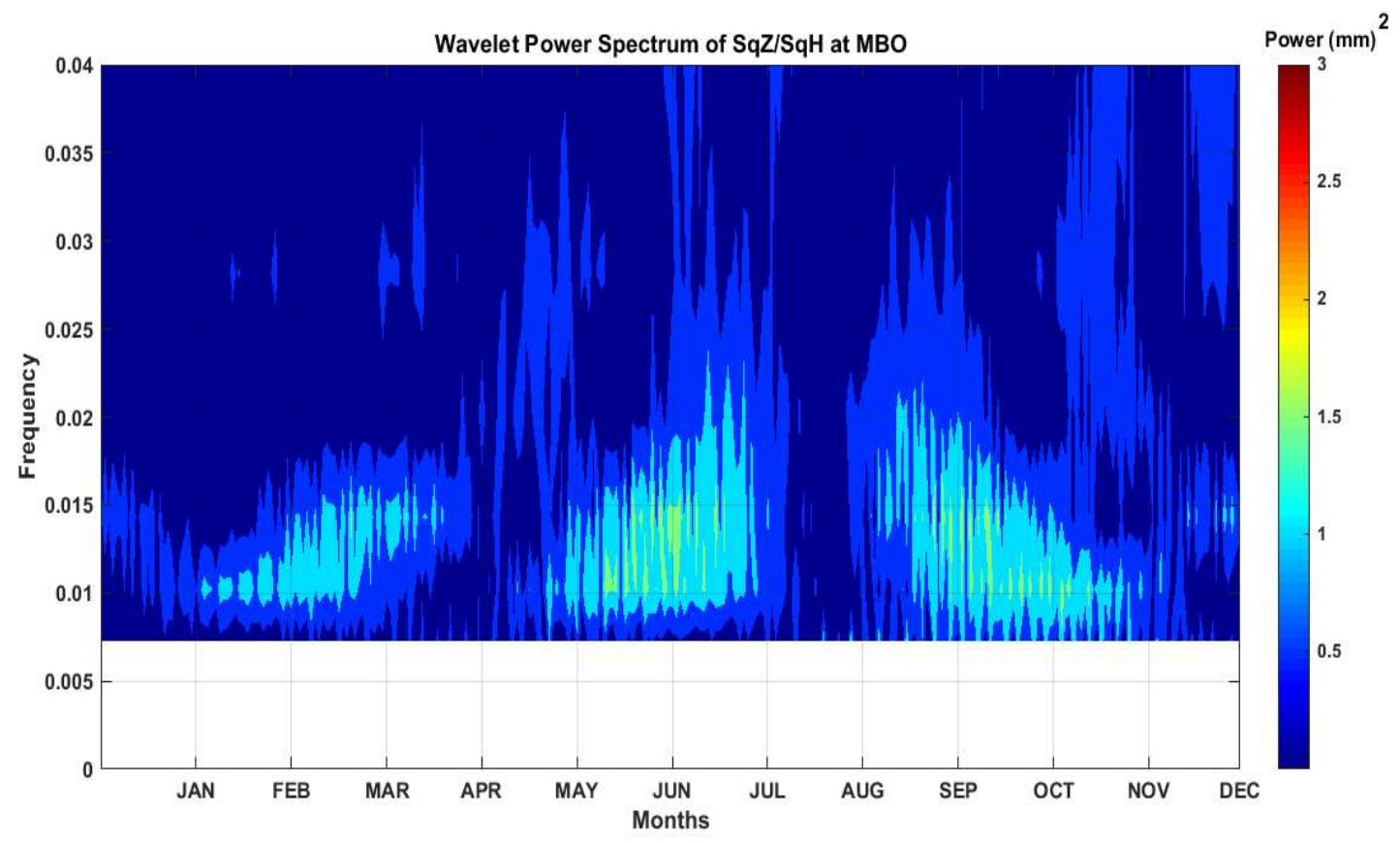


(c)

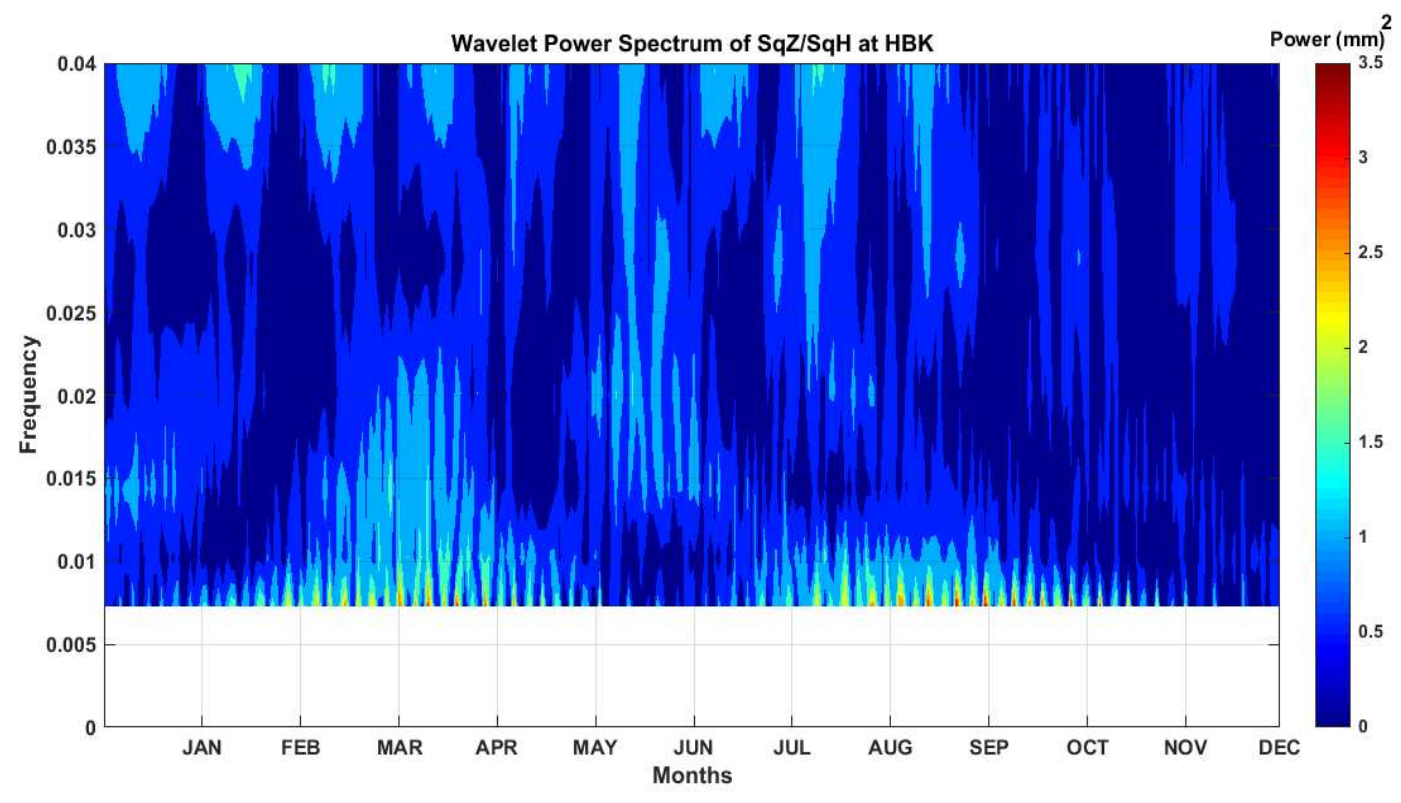

(d)

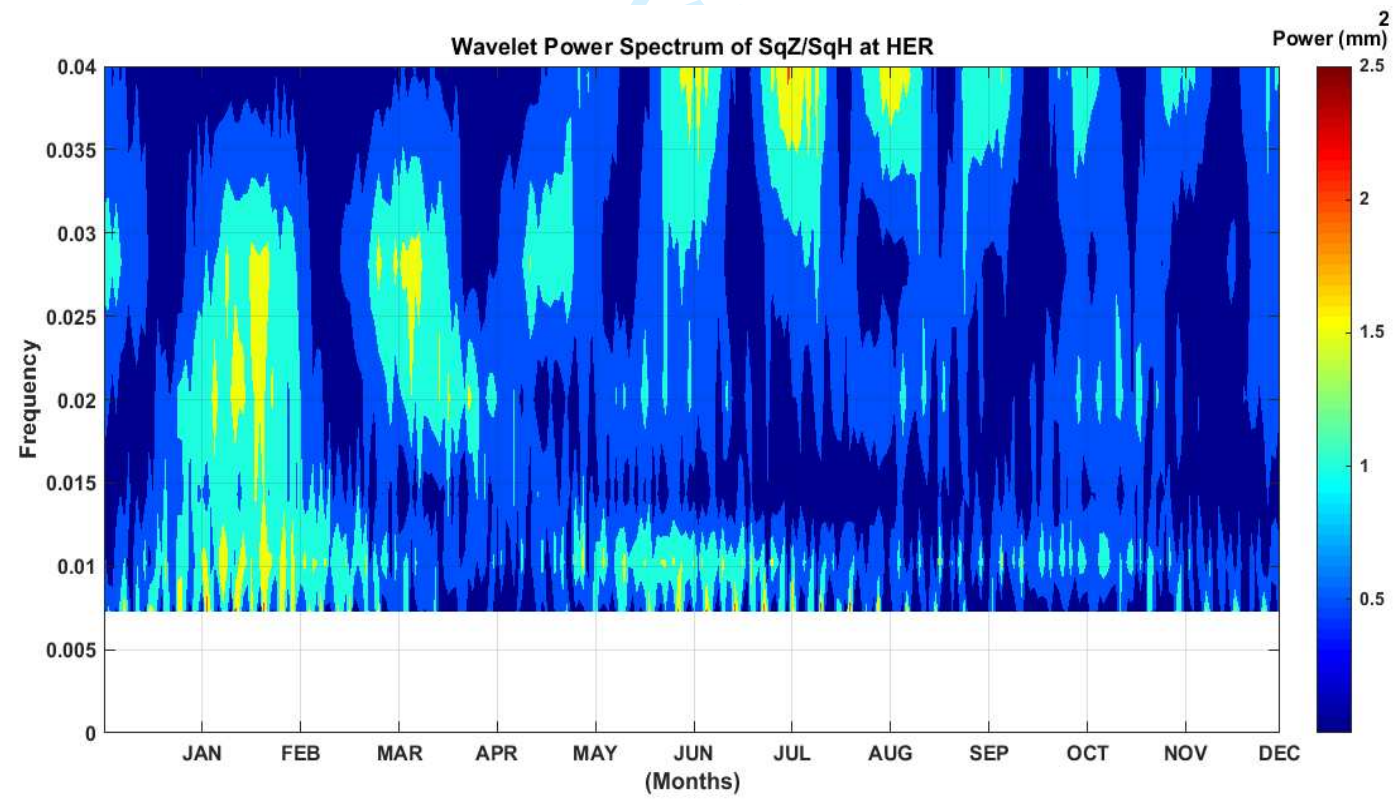


(e)

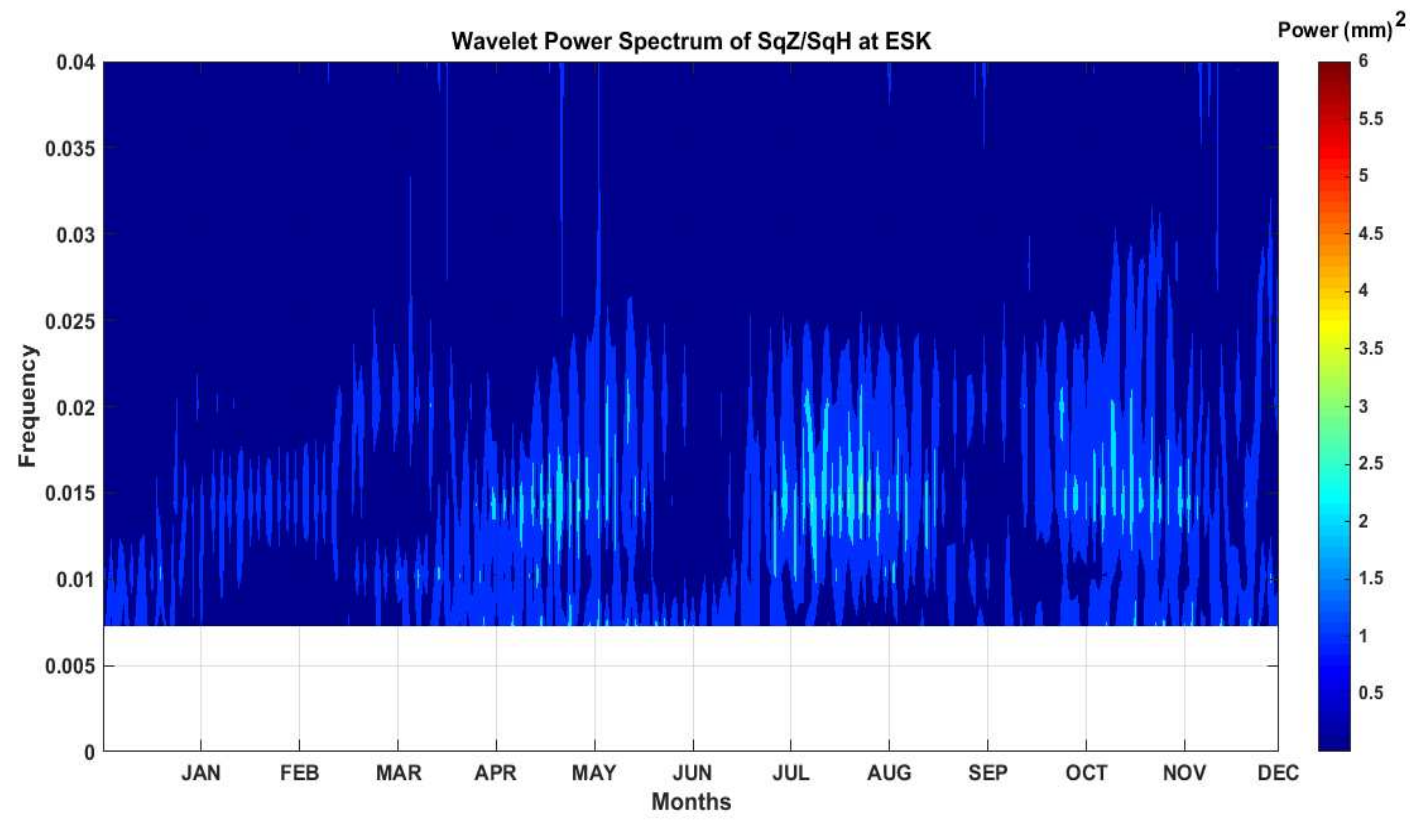

(f)

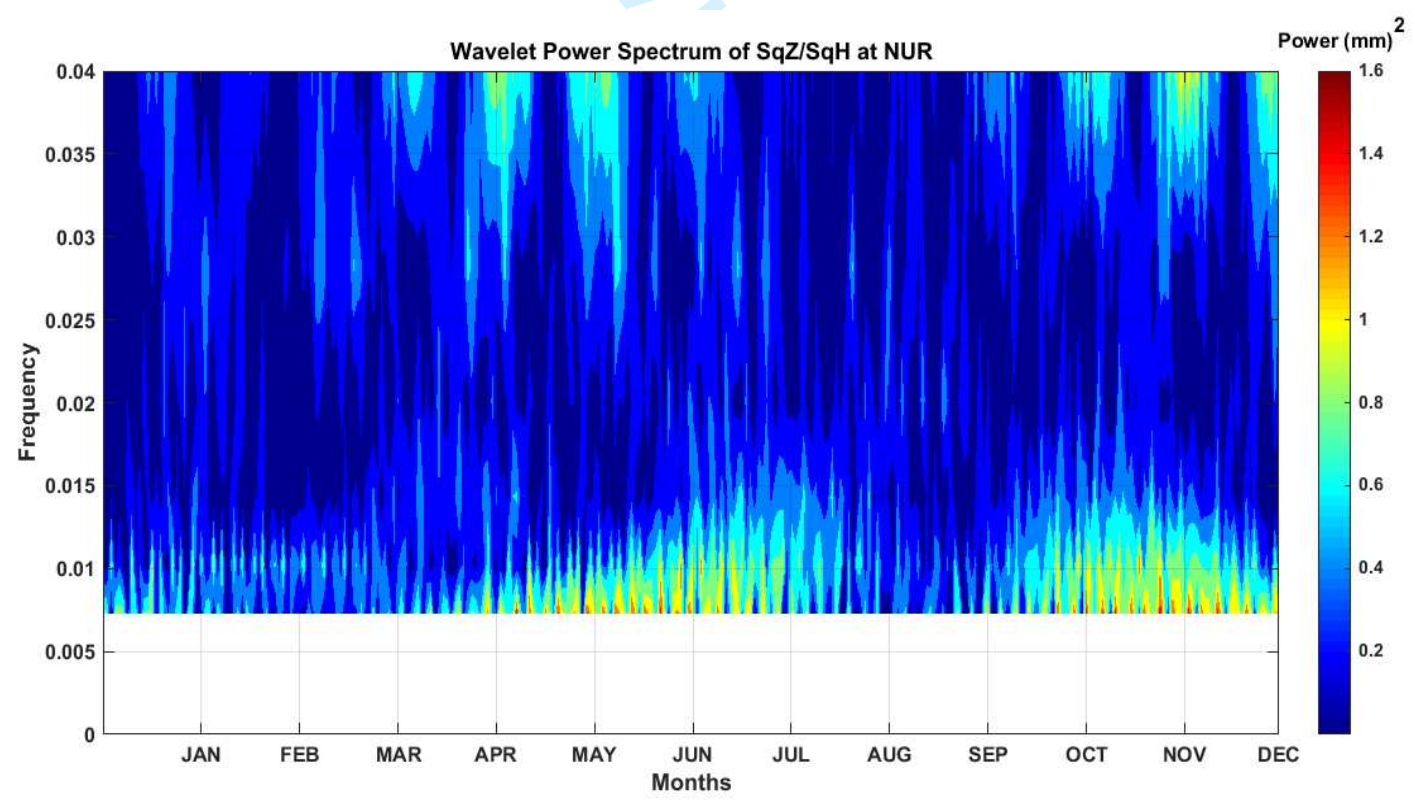

Figure 4 (a-f). Wavelet spectrum analyses of SqH/SqZ at BNG, MBO, HBK, HER, ESK and NUR respectively during the solar maximum year of 2001. 
Canadian Journal of Physics

Page 22 of 22

Tables Caption

Table 1. Geographic and geomagnetic coordinates of geomagnetic observatories.

\begin{tabular}{lccccc}
\hline Stations & Abbrev & $\begin{array}{c}\text { Geog. lat. } \\
(\mathrm{deg})\end{array}$ & $\begin{array}{c}\text { Geog. Long. } \\
(\mathrm{deg})\end{array}$ & $\begin{array}{c}\text { Geomag. lat. } \\
(\mathrm{deg})\end{array}$ & $\begin{array}{c}\text { Geomag. Long. } \\
(\mathrm{deg})\end{array}$ \\
\hline Hermanus & HER & -34.43 & 19.23 & 42.39 & 82.15 \\
Hartebeesthoek HBK & -25.88 & 27.71 & 36.31 & 94.72 \\
Bangui & BAN & 4.33 & 18.57 & -5.27 & 90.13 \\
bour & HBO & 14.38 & 343.03 & 2.06 & 58.24 \\
Eskladimur & ESR & 55.32 & 365.80 & 52.89 & 77.76 \\
Nurmijarvi & NOR & 60.51 & 24.66 & 56.75 & 102.47 \\
\hline
\end{tabular}

https://mc06.manuscriptcentral.com/cjp-pubs 